\title{
Prostate Cancer Screening in the Fit Chilean Elderly: a Head to Head Comparison of Total Serum PSA versus Age Adjusted PSA versus Primary Circulating Prostate Cells to Detect Prostate Cancer at Initial Biopsy
}

\author{
Nigel P Murray ${ }^{1,2 *}$, Eduardo Reyes ${ }^{3}$, Nelson Orellana ${ }^{4}$, Cynthia Fuentealba ${ }^{4}$, \\ Omar Jacob ${ }^{4}$
}

\begin{abstract}
Background: Prostate cancer is predominately a disease of older men, with a median age of diagnosis of 68 years and $71 \%$ of cancer deaths occurring in those over 75 years of age. While prostate cancer screening is not recommended for men $>70$ years, fit elderly men with controlled comorbidities may have a relatively long life expectancy. We compare the use of age related PSA with the detection of primary malignant circulating prostate cells $\mathbf{m C P C}$ s to detect clinically significant $\mathrm{PC}$ in this population. Materials and Methods: All men undergoing PC screening with a PSA $>4.0 \mathrm{ng} / \mathrm{ml}$ underwent TRUS 12 core prostate biopsy (PB). Age, PSA, PB results defined as cancer/no-cancer, Gleason, number of positive cores and percentage infiltration were registered. Men had an $8 \mathrm{ml}$ blood sample taken for $\mathrm{mCPC}$ detection; mononuclear cells were obtained using differential gel centrifugation and mCPCs were identified using immunocytochemistry with anti-PSA and anti-P504S. A mCPC was defined as a cell expressing PSA and P504S; a positive test as at least one mCPC detected/sample. Diagnostic yields for subgroups were calculated and the number of avoided PBs registered. Esptein criteria were used to define small grade tumours. Results: A total of 610 men underwent $P B, 398$ of whom were aged $<70 \mathrm{yrs}$. Men over 70 yrs had: a higher median PSA, $6.24 \mathrm{ng} / \mathrm{ml}$ versus $5.59 \mathrm{ng} / \mathrm{ml}(\mathrm{p}=0.04)$; and a higher frequency of cancer detected 90/212 $(43 \%)$ versus $134 / 398(34 \%)(p=0.032)$. Some 34/134 cancers in men $<70 \mathrm{yrs}$ versus $22 / 90(24 \%)$ of men $>70$ yrs complied with criteria for active surveillance. CPC detection: $154 / 398(39 \%)$ men $<70 y r s$ were CPC (+), specificity for cancer $86 \%$, sensitivity $88 \%, 14 / 16$ with a false (-) result had a small low grade PC. In men $>70$ years, 88/212 (42\%) were CPC (+); specificity $92 \%$, sensitivity $87 \%, 10 / 12$ with a false (-) had small low grade tumours. False $(+)$ results were more common in younger men $36 / 154$ versus $10 / 88(p<0.02)$. With a PSA cutoff of $6.5 \mathrm{ng} / \mathrm{ml}$, in men $<70 \mathrm{yrs}, 108 \mathrm{~PB}$ would be avoided, missing 56 cancers of which 48 were clinically significant. Using CPC detection, 124 biopsies would be avoided, missing only 2 clinically significant cancers. In men $>70$ yrs using a PSA $>6.5 \mathrm{ng} / \mathrm{ml}$ would have resulted in $108 \mathrm{~PB}$ with $34 \mathrm{PC}$ detected, of which $14(41 \%)$ were small low grade tumours. Conclusions: The use of CPC detection in the fit elderly significantly decreases the number of PBs without missing clinically significant cancers, indicating superiority to the use of age-related PSA.
\end{abstract}

Keywords: Prostate cancer - screening - elderly - circulating prostate cells - PSA

Asian Pac J Cancer Prev, 16 (2), 601-606

\section{Introduction}

Prostate cancer is the most frequent cancer in the male population in the USA (Jemal et al., 2008) and Europe (Ferlay et al., 2007), and is the first cause of male cancer death in the USA (Jemal et al., 2008) and third cause of male cancer death in Europe (Ferlay et al., 2007). It is predominantly a disease of older men, with a median age at diagnosis of 68 years and $71.2 \%$ of deaths caused by prostate cancer occur in men over 75 years (Ries et al., 2009) and there is evidence that prostate cancer is more aggressive in older men (Sun et al., 2009). Screening for prostate cancer remains controversial, the two large studies published from the USA and Europe produced different results (Andiole et la, 2009, Schroder et al., 2009). As a consequence the American Urology Association guidelines do not recommend screening in men over 70 years or with a life expectancy of less than 10 years (Carter et al., 2013), although they recognize that some elderly men who are healthy may benefit from screening. However they also state that the ratio of harm to benefit increases with age, and that the likelihood of 
over diagnosis is extremely high, particularly in those with low risk disease (Carter et al., 2013). The European Association of Urology and NCCN indicate that radical treatment is appropriate in men with a life expectancy of 10 years (Heidenrich et al., 2012, NCCN 2014), and thus screening may be appropriate, especially as pathological and oncological outcomes in men $>70$ years treated by radical prostatectomy are not significantly different than those of younger patients (Mitsuzuka et al, 2014) and advancing age increases cancer specific mortality (Gandagalia et al, 2014)..

Although there are published values for median life expectancy for age (Walter et al., 2001) they are not useful for individual purposes. Similarly the chronological age is not the same as the biological age in the elderly. The International Society of Geriatric Oncology classified the elderly into four groups according to co-morbidities, functional status and weight loss in the previous three months. Group 1 comprises healthy men, with controlled comorbidities, full independence in daily living and good nutritional status, thus a 75 year old man in Group 1 is expected to live for at least 14.2 years, in comparison with less than 4.9 years for a man in Group 3, classified as frail (Droz et al, 2014). Therefore, if it is considered that screening is appropriate in men classified as elderly but healthy, there is a need for a biomarker that detects clinically significant cancer that would, if left untreated, affect the survival or quality of life of the patient. The serum total PSA is the only widely used biomarker used for prostate cancer screening, although it is prostate specific an elevated level is not specific for prostate cancer, being increased in benign

pathologies (Bozeman et al,2002; Punglia et al., 2006). Consequently, approximately $70 \%$ of men with an increased serum PSA, defined as $>4.0 \mathrm{ng} / \mathrm{mL}$, do not have prostate cancer (Jemal et al., 2008) and thus undergo unnecessary prostate biopsies. In elderly patients the specificity of the test decreases as a result of benign hyperplasia and chronic prostatitis (Gann et al., 1995), to compensate for this age related serum total PSA levels were proposed.

The detection of malignant circulating prostate cells ( $\mathrm{mCPC}$ ) could be one candidate for the early detection of PC. In men with prostate cancer there is, at least, one subpopulation of cancer cells that disseminate early, firstly to the neurovascular structures and then to the circulation (Moreno et al., 1992). The number of these cells is very small; however these mCPC can be detected using immuocytochemistry with a combination of anti-P504S (methyl-acyl-CoA racemase) and anti-PSA monoclonal antibodies. The use of the biomarker P504S, although not prostate specific (Zhou et al., 2002), has facilitated the differentiation between normal, dysplastic and malignant tissues in prostate biopsy samples. Normal or benign cells do not express P504S, whereas cells arising from prostatic intraepithelial neoplasia (PIN) or cancer are positive (Beach et al., 2002).

In this article we analyze prospectively a group of patients, including fit elderly men $>70$ years who were referred for a prostate biopsy for the suspicion of prostate cancer; based on an increased PSA of $\geq 4$.0ng/mL or a DRE suggestive of a malignant lesion. The results an 12 core ultrasound guided transrectal PB were compared with the detection of $\mathrm{mCPC}$. The objective was to determine the diagnostic yield of the $\mathrm{mCPC}$ as a method to detect prostate cancer in men fulfilling criteria for a prostate biopsy and compare with a PSA value of $>4.0 \mathrm{ng} / \mathrm{ml}$ and aged related PSA value of $6.5 \mathrm{ng}</ \mathrm{ml}$.

\section{Materials and Methods}

We prospectively studied all men undergoing prostate cancer screening at the Urology Department, Hospital de Carabineros de Chile between January 2011 and September 2013. Men with a total serum PSA of $\geq 4.0 \mathrm{ng} /$ $\mathrm{ml}$ and/or a digital rectal examination (DRE) abnormal or suspicious of cancer, defined as the presence of a nodule, areas of indurations, or asymmetry in the size of the lateral lobes (Campbell et al., 2011) were referred for an initial transrectal ultrasound guided (TRUS) prostate biopsy. The biopsy results were classified as having cancer or nocancer. The data base created included age and serum PSA, and the results of the biopsy if indicated. Blood samples were taken from all men for the detection of mCPCs.

\section{PSA Values and Prostate Biopsy:}

Total PSA was measured before DRE (Siemens,AdviaCentaurXR, total PSA); all biopsies were 12-core ultrasound guided; when cancer was detected, the number of cores positive for cancer and the maximum percentage of infiltration by cancer were registered. Prostate biopsies were analyzed by a single pathologist.

\section{Detection of $m C P C$}

For detection of primary malignant circulating prostate cells (mCPCs), immediately before a DRE, an $8 \mathrm{~mL}$ venous blood sample was taken in a tube containing EDTA (Beckinson-Vacutainer). Samples were maintained at $4^{\circ} \mathrm{C}$ and processed within 48 hours. The serum total PSA, prostate biopsy and CPC detection were independently analyzed, with the evaluators being blinded to the clinical details and results of the serum PSA, biopsy or CPC test.

Mononuclear cells were obtained by differential centrifugation using Histopaque 1,077 (Sigma-Aldrich), washed, and resuspended in $50 \mu \mathrm{L}$ of autologous plasma. $25 \mu \mathrm{L}$ aliquots were used to make slides (silanized, DAKO, USA), dried in air for 24 hours, and fixed in a solution of $70 \%$ ethanol, $5 \%$ formaldehyde, and $25 \%$ phosphate buffered saline $\mathrm{pH}$ 7.4.

\section{Immunocytochemistry}

mCPCs were detected using a monoclonal antibody directed against PSA, clone 28A4 (Novocastro Laboratory, UK), and identified using an alkaline phosphatase-anti alkaline phosphatase based system (LSAB2, DAKO, USA), with new fuchsin as the chromogen. Positive samples underwent a second process with anti- P504S clone 13H4 (DAKO, USA) and were identified with a peroxidase based system(LSAB2,DAKO, USA) with DAB (3,3-diaminobenzidine tetrahydrochloride) as the chromogen.

A mCPC was defined according to the criteria of 
ISHAGE (International Society of Hemotherapy and Genetic Engineering) (Borgen et al., 1999) and the expression of P504S according to the Consensus of the American Association of Pathologists (Ruben et el, 2002).

A malignant CPC was defined as a cell that expressed PSA and P504S, a benign prostate cell could express PSA but not P504S, and leucocytes could be P504S positive or negative but did not express PSA. A test was considered positive when at least 1 cell $/ 4 \mathrm{~mL}$ of blood was detected. P504S was not used alone as leucocytes can be positive for this marker. Patients with benign CPCs were considered as being negative for the test. Prostate cancer cells as well as PIN cells express P504S whereas benign cells do not; thus cells expressing PSA and P504S were considered to be malignant, whereas cells expressing PSA but not P504S were considered to be benign (Murray et al., 2013). (Figure 1A-C).

\section{Analysis of the results}

The frequency of mCPC detection was compared with age and serum total PSA levels for all men. Those undergoing prostate biopsy were divided into two groups; Group I those men $<70$ years and Group II men $\geq 70$ years, data was analyzed using the cutoff value of total PSA of $4,0 \mathrm{ng} / \mathrm{ml}$ and $6,5 \mathrm{ng} / \mathrm{ml}$ and using the presence or absence of $\mathrm{mCPC}$.

The discrimination of the differing diagnostic tests was defined using the normal parameters: true positive (TP); false positive (FP), false negative (FN), and true negative (TN). The predictive values, positive (PPV) as well as negative (NPV), were evaluated, as well as the positive and negative likelihood ratios (+LR and -LR, resp.). In men with FN CPC detection the details of the cancer were analyzed. The potential number of biopsies

\section{A}

1B

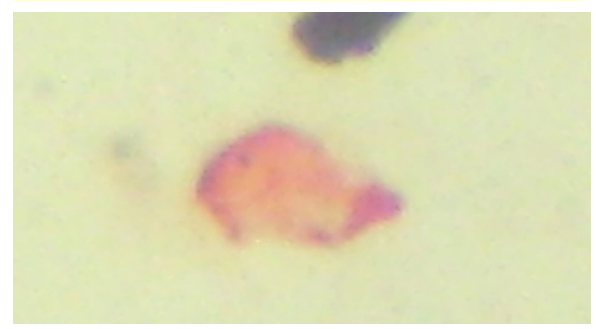

$1 \mathrm{C}$

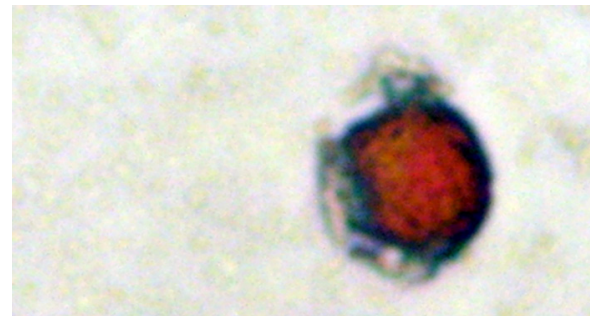

Figure 1A-C. Photo-micrographs of CPCs. 1A) Leukocyte: PSA negative, $\mathrm{P} 594 \mathrm{~S}$ positive; 1B) Benign CPB: PSA positive, P504S negative; 1C) Malignant CPC: PSA positive, P504S positive avoided for each method was calculated. In addition, using the criteria of Epstein et al. (1994), the number of cancers needing active treatment and active observation were registered for each test to determine the clinical significance of each test used.

\section{Statistical analysis}

Descriptive statistics were used for demographic variables, expressed as mean and standard deviation in the case of continuous variables with a normal distribution. In case of an asymmetrical distribution the

median and interquartile range (IQR) values were used. Noncontiguous variables were presented as frequencies. The Shapiro-Wilk test was used to determine a normal distribution. The Student t-Test was used to compare continuous variables with a normal distribution, the Mann-Whitney test for ordinate and continuous variables with a non-normal distribution, and the Chi-squared test for the differences in frequency. The diagnostic yield for the test detecting CPCs and PSA score were analyzed using standard parameters. For this purpose patients were classified as having or not having prostate cancer. Statistical significance was defined as a $p$ value less than 0.05 to two-sided. Analysis was performed using the Stata 11.0 program (StataCorp LP, College Station, Texas, USA).

\section{Results}

\section{Total population}

1198 men with a mean age of $64.7 \pm 10.2$ years participated in the study, with a median serum PSA of $4.42 \mathrm{ng} / \mathrm{ml}$ (inter-quartile range $1.71-6.30 \mathrm{ng} / \mathrm{ml}$. Of these men 685 had a PSA $>4.0 \mathrm{ng} / \mathrm{ml}$ and prostate biopsy was recommended.

\section{Men with prostate biopsy}

A total of $610 / 685(89.1 \%)$ men with a PSA $\geq 4.0 \mathrm{ng} / \mathrm{ml}$ underwent trans-rectal 12 core ultrasound guided biopsy during the study period, the 75 men underwent biopsy at a later date. Group I men younger than 70 years: 398 men with a mean age of $60.2 \pm 6.2$ years, with a median total serum PSA of 5.59ng/ml (IQR 4.44-7.69ng/ml). 134/398 $(33.7 \%)$ had prostate cancer detected on biopsy. 34/134 $(25.4 \%)$ of men with prostate cancer complied with the Epstein criteria for active observation. Group II men at least 70 years and older: 212 men with a mean age of $74.2 \pm 4.5$ years and a median serum PSA of $6.24 \mathrm{ng} / \mathrm{ml}$ (IQR 4.87-9.34). 90/212 (42.5\%) had prostate cancer detected on biopsy. 22/90 (24.4\%) of men with prostate cancer complied with the Epstein criteria for active observation. Group II men had a significantly higher

Table 1. Comparison of mCPC with Results of the Prostate Biopsy

\begin{tabular}{lccc}
\hline & $\begin{array}{c}\text { Biopsy Positive } \\
\text { for Cancer }\end{array}$ & $\begin{array}{c}\text { Biopsy Negative } \\
\text { for Cancer }\end{array}$ & Total \\
\hline mCPC positive & 118 & 36 & 154 \\
mCPC negative & 16 & 228 & 244 \\
\hline Total & 134 & 264 & 398 \\
\hline
\end{tabular}


Table 2. Diagnostic Yield for $\mathrm{mCPC}$ in Men $<70$ Years, Men $\geq 70$ years and Age Adjusted PSA

\begin{tabular}{|c|c|c|c|c|c|c|}
\hline & \multicolumn{2}{|c|}{$<70$ yrs mCPC } & \multicolumn{2}{|c|}{$\geq 70$ yrs mCPC } & \multicolumn{2}{|c|}{$\mathrm{PSA}>6.5 \mathrm{ng} / \mathrm{ml}$} \\
\hline & Value $\%$ & $95 \% \mathrm{CI}$ & Value & $95 \% \mathrm{CI}$ & Value & $95 \% \mathrm{CI}$ \\
\hline specificty & 86.4 & $81.6-90.3$ & 91.8 & $85.4-96.0$ & 61.0 & $51.6-69.9$ \\
\hline sensitivity & 88.1 & $81.3-93.0$ & 86.7 & 77.9-92.9 & 62.2 & $51.4-72.2$ \\
\hline PPV & 76.6 & $69.1-83.1$ & 88.6 & $80.1-96.4$ & 54.9 & $44.7-64.8$ \\
\hline NPV & 93.4 & $89.6-96.2$ & 90.3 & $83.7-94.9$ & 67.9 & $58.2-76.7$ \\
\hline $\mathrm{LR}(+)$ & 6.46 & $4.74-8.80$ & 10.57 & $5.81-19.3$ & 1.60 & $1.21-2.11$ \\
\hline LR (-) & 0.14 & $0.09-0.22$ & 0.15 & $0.09-0.25$ & 0.62 & $0.46-0.84$ \\
\hline
\end{tabular}

*PPV=positive predictuve value; NPV=negative predictive value; $\mathrm{LR}(+)=$ positive liklihood ratio; $\mathrm{LR}(-)=$ negative liklihood ratio

median PSA $(\mathrm{p}=0.04)$ and a higher frequency of cancer detected $(\mathrm{p}=0.032)$. There was no significant difference in the frequency of men with prostate cancer complying with the criterion of active surveillance $(\mathrm{p}=0.88)$.

\section{Detection of $m C P C s$}

Group I: $154 / 398$ (38.7\%) had mCPCs detected; the presence/absence of $\mathrm{mCPC}$ in comparison with the results of the prostate biopsy is shown in Table 1. Of the 16 men mCPC negative with a positive biopsy, 14/16 (87.5\%) complied with the criterion for active observation. The diagnostic yield is shown in Table 2 .

\section{Group II}

88/212 (41.5\%) had mCPC detected, the presence/ absence of $\mathrm{mCPC}$ in comparison with the results of the prostate biopsy is shown in Table 3 . Of the 12 men mCPC negative with a positive biopsy, 10/12 (83.3\%) complied with the criterion for active observation. The diagnostic yield is shown in Table 2

The frequency of men mCPC (+) biopsy (-) (false positive) was significantly higher in men $<70$ years, $36 / 154(23.4 \%)$ versus $10 / 88(11.3 \%)(\mathrm{p}<0.02)$. In men mCPC (-) biopsy (+) (false negative) there was no difference 16/244 (6.6\%) versus 12/124 (9,7\%) ( $\mathrm{p}=0.29)$ respectively. In clinical terms $14 / 16$ of men $<70$ years with a false negative test had small volume low grade tumors, and in men $\geq 70$ years $10 / 12$ had similar tumors $(\mathrm{p}=0.46)$, these tumors complied with the criterion for active observation.

Using a cutoff point of $6.5 \mathrm{ng} / \mathrm{ml}$ in men $\geq 70$ years to recommend prostate biopsy

Using a cutoff value of $6.5 \mathrm{ng} / \mathrm{ml}$ in men $>70$ years would have resulted in 108/212 (50.9\%) elderly men undergoing biopsy, of whom 34/108 (31.5\%) had a positive biopsy for cancer (Table 4). Of these 34 cancers, $14(41 \%)$ complied with the criterion for active observation. With this cutoff value, 104 men $>70$ years would not have undergone a biopsy, missing 56 cancers, of which only $8 / 56(14.2 \%)$ complied with the criterion of active observation. The frequency of detected cancers was significantly higher in the group with a PSA of between $4.0-6.5 \mathrm{ng} / \mathrm{ml}, 56 / 104$ (53.9\%) versus 34/108 (31.5\%) ( $\mathrm{p}=0.001 \mathrm{Chi}$ squared), as was the frequency of clinically significant cancers, 48/56 (85.6\%) versus 20/34 (58.8\%) ( $p=0.009$, Chi squared).

The diagnostic yield of using a cutoff point of $6.5 \mathrm{ng} /$ $\mathrm{ml}$ and not $4.0 \mathrm{ng} / \mathrm{ml}$ is shown in Table 2 .
Table 3. Comparison of $\mathrm{mCPC}$ with Result of the Prostate Biopsy

\begin{tabular}{lccr}
\hline & $\begin{array}{c}\text { Biopsy Positive } \\
\text { for Cancer }\end{array}$ & $\begin{array}{c}\text { Biopsy Negative } \\
\text { for Cancer }\end{array}$ & Total \\
\hline mCPC posiitve & 78 & 10 & 88 \\
mCPC negative & 12 & 112 & 124 \\
\hline Total & 90 & 122 & 212 \\
\hline
\end{tabular}

Table 4. Age Adjusted PSA of $\geq 6.5 \mathrm{ng} / \mathrm{ml}$ Versus 4.0$<6.5 \mathrm{ng} / \mathrm{ml}$ and Prostate Biopsy Results

\begin{tabular}{lccc}
\hline & $\begin{array}{c}\text { Biopsy Positive } \\
\text { for Cancer }\end{array}$ & $\begin{array}{c}\text { Biopsy Negative } \\
\text { for Cancer }\end{array}$ & Total \\
\hline $\mathrm{mPSA} \geq 6.5 \mathrm{ng} / \mathrm{ml}$ & 34 & 74 & 108 \\
PSA $4.0-<6.5 \mathrm{ng} / \mathrm{ml}$ & 56 & 48 & 104 \\
\hline Total & 90 & 122 & 212 \\
\hline
\end{tabular}

Comparing $m C P C$ detection with a PSA cutoff value of $6.5 \mathrm{ng} / \mathrm{ml}$.

Using a cutoff of $6.5 \mathrm{ng} / \mathrm{ml}$ and not $4.0 \mathrm{ng} / \mathrm{ml}$ resulted in $56 / 90(62.2 \%)$ of cancers not being detected, of which $48 / 56(85.7 \%)$ complied with the recommendations for active treatment or in other words clinically significant. In contrast, over the whole range of PSA values over $4.0 \mathrm{ng} / \mathrm{ml}$ the use of $\mathrm{mCPC}$ detection failed to detect only 2 clinically significant cancers, a significant difference $(\mathrm{p}<0.001)$. In terms of biopsies avoided, the cutoff of $6.5 \mathrm{ng} / \mathrm{ml}$ would have resulted in 108 less biopsies $(50.9 \%)$ being performed, in comparison using $\mathrm{mCPC}$ detection 124 biopsies would have been avoided (58.5\%), significantly more biopsies would have been avoided with mCPC detection $(\mathrm{p}=0.03)$.

\section{Discussion}

There is a group of men $>70$ years, who in spite of not complying with prostate cancer screening recommendations, are, according to the International Society of Geriatric Oncology, healthy men with controlled comorbidities, full independence in daily living and good nutritional status and are expected to live on average for at least 14.2 years. It would seem inappropriate that these men are not considered for screening and as a result treatment of a detected cancer. The role of age in decision making is particularly problematic, published data suggest that otherwise healthy older men with clinically significant cancers may not be receiving potentially life prolonging therapy as a result of the perception that they are unlikely to benefit from treatment (Alibhai et al., 2002). However, 
there is evidence that potentially curative therapy may lead to positive health outcomes for men up to least 80 years with moderately or poorly differentiated localized prostate cancer (Becker et al, 2014). Population based studies have shown that a greater frequency of PSA testing in men $>70$ years in the 5 years before prostate cancer diagnosis is associated with a lower likelihood of being diagnosed with metastatic prostate cancer and improved overall and prostate cancer specific survival (Hu et al, 2014).

Autopsy studies have shown that men older than 70 years have significantly larger cancers, higher Gleason scores, and more advanced stage (Delongchamps et al., 2009). Although total serum PSA is a significant predictor for prostate cancer in men over 75 years (Verim et al., 2013), PSA based screening is currently based on the urologists opinion and age alone has been a major influence on this opinion (Situmorang et al., 2012). The frequency of men with an elevated PSA and benign biopsy is country dependent, (Belbase NP et al., 2013), may be significantly different between rural and metropolitan populations in the same country (Lalitha et al., 2012). Thus an ideal biomarker should be able to differentiate between benign disease and prostate cancer, especially in this older age group. The use of $\mathrm{mCPC}$ detection may be of use across differing populations as the frequency of mCPC detection increases both with serum PSA and age (Murray et al., 2014), and has a high negative predictive value, not detecting low grade small volume tumors (Murray et al., 2014a).

Our results show that clinically significant prostate cancer was detected more frequently in elderly Chilean men with a serum PSA $>4.0 \mathrm{ng} / \mathrm{ml}$ when compared with the younger age group. The results also show that those elderly patients complying with the criteria for active surveillance are in the minority, and thus the concern of over diagnosing and over treating indolent cancer may be overestimated for the group as a whole.

Using a PSA cutoff value of $6.5 \mathrm{ng} / \mathrm{ml}$ in men $>70$ years would have reduced the number of prostate biopsies but missed the majority of clinically significant cancers. Low grade tumors and benign disease were more common in this group, as compared with elderly men with a PSA of $4.0-6.5 \mathrm{ng} / \mathrm{ml}$.

In contrast the use of sequential mCPC testing significantly reduced the number of prostate biopsies while detecting clinically significant cancers. Older men had significantly less false positive CPC testing; it may be that in younger men with small volume, high grade tumors the biopsy core did not detect the cancer even though dissemination of cancer cells to the blood occurred.

An ideal biomarker for the detection of prostate cancer is one that detects clinically significant cancers, does not detect indolent cancer, and has a high negative predictive value to avoid unnecessary biopsies. Prostate biopsies have associated risks; Prostate biopsies have associated risks; with a 30 day complication rate of $3.7 \%$, especially in those over 85 years or with three or more comorbidities and has increased in recent years predominantly as a result of infection (Anastasiadis et al, 2014) and thus avoiding biopsies is a worthwhile aim, if the number of clinically significant cancers detected is not prejudiced.
The use of sequential mCPC detection appears to fulfill these criteria, having a higher diagnostic yield in comparison with total serum PSA. What is probably more important is that the NPV of $90.3 \%$ in a sample of patients $>70$ years, with a prevalence of cancer of $42.5 \%$ and a suspicion of prostate cancer requiring a biopsy showed that the absence of CPCs had a high discriminating power. This suggests that men with an increased serum PSA and/ or abnormal DRE but negative CPC could be considered of being at low risk and thus a biopsy might not be necessary. This is in contrast with the use of age-related PSA, the recommended cutoff value of $6.5 \mathrm{ng} / \mathrm{ml}$ did not fulfill these requirements; although decreasing the number of biopsies; the number of clinically important prostate cancers that would be missed was significant.

Results using the detection of circulating prostate cells with different methodologies have been discordant. This problem has been extensively reviewed as to the advantages and disadvantages of each method (Fehm et al 2005, Patenleukou et al., 2009). The widely accepted concept that all positive cytokeratin and/or EpCAM and CD45 negative cells with a nucleus in cancer patients are circulating tumor cells (CTCs) has imposed a clear bias on the study of CTCs. Mainly the failure to include tumor cells that have reduced or absent cytokeratin and/or EpCAM expression and the failure to identify such cell types limit investigations into additional tumor types. EpCAM is expressed in most but not all tumors (Went et al., 2004); there is downregulation with cancer progression and metastasis and cytokeratins are heterogeneously expressed in tumor cells and also may be downregulated during disease progression or in poorly differentiated tumors. During the progression of epithelial to mesenchymal transition both markers are downregulated (PaterliniBrechot, 2007). Benign CPCs can be found in men with benign hyperplasia and prostatitis which may explain the high detection rate in controls, but these cells do not express P504S (Murray et al., 2013.)

In conclusion, in this sample of fit elderly Chilean men the use of an age adjusted PSA value of $6.5 \mathrm{ng} /$ $\mathrm{ml}$ to recommend a prostate biopsy for the suspicion of prostate cancer did not comply with the criteria of ideal biomarker, that more men with a PSA in the range 4.0-6.5ng/ml had clinically significant cancers. The use of $\mathrm{mCPC}$ detection however, decreased the number of potential biopsies without missing a significant number of clinically important prostate cancers in this group of elderly fit Chilean men and deserves studies with a larger number of patients to confirm these results as well as multicenter studies.

\section{Acknowledgements}

Mrs. Ana Maria Palazuelos for her help in the writing of this paper.

\section{References}

Alibhai SM, Naglie G, Nam R, et al (2003). Do older men benefit from curative therapy of localized prostate cancer? J Clin Oncol, 21, 3318-27 
Nigel P Murray et al

Andiole GL, Grubb RL III, Buys SS, et al (2009). Mortality results from a randomized prostate cancer screening trial. NEJM, 360, 1310-19.

Anastasiadis E, van der Meulen J, Emberton M (2014). Hospital admissions after TRUS biopsy of the prostate in men diagnoses with prostate cancer: A database analysis in England. Int J Urol, (in Press).

Beach R, Gown AM, Peralta-Venturina MN et al (2002). P504S immunohistochemical detection in 405 prostatic specimens including 376 18-guage needle biopsies. Am J Surg Pathol, 26, 1588-96.

Becker D, Ryemon S, Gross J, et al (2014). Cancer trends among the extreme elderly in the era of cáncer screening. J Geriatr Oncol, 1, 408-14.

Belbase NP, Agrawal CS, Pokharel PK, et al (2013). Prostate cancer screening in a healthy population cohort in Eastern Nepal: an explanatory trial study. Asian Pac J Cancer Prev, 14, 2835-8.

Borgen E, Naume B, Nesland JM, et al (1999). Standardization of the immunocytochemical detection of cancer cells in $\mathrm{BM}$ and blood. I. Establishment of objective criteria for the evaluation of immunostained cells, Cytotherapy, 1, 377-388.

Bozeman CB, Carver BS, Eastham JA, et al (2002). Treatment of chronic prostatitis lowers serum prostate specific antigen, J Urol, 167, 1723-6.

Campbell MF, Wein AJ, Kavoussi LR (2011). Campbell's Urology. V, Section II, chapter, 3, 2011.

Carter HB, Albertsen PC, Barry MJ, et al (2013). Early detection of prostate cancer: AUA guideline. J Urol, 190, 419-26

Delongchamps NB, Wang CY, Chandan V, et al (2009). Pathological characteristics of prostate cancer in elderly men. $J$ Urol, 182, 927-30

Droz JP, Aapro M, Balducci L et al (2014). Management of prostate cancer in older patients: updated recommendations of a working group of the International Society of Geriatric Oncology. Lancet Oncol, 15, e404-414.

Epstein JI, Walsh PC, Carmichael M (1994). Pathologic and clinical findings to predict tumor extent of nonpalpable (stage T1c) prostate cancer, JAMA, 271, 368-74.

Fehm T, Solomayer EF, Meng S et al (2005). Methods for isolating circulating epithelial cells and criteria for their classification as carcinoma cells, Cytotherapy, 7, 171-85.

Ferlay J, Autier P, Bonial M et al (2007). Estimates of cancer incidence and mortality in Europe in 2006. Ann Oncol, 18, 581-92

Gandaglia G, Karakiewicz PI, Abdollah F, et al (2014). The effect of age at diagnosis on prostate cancer mortality: A grade for grade and stage for stage analysis. Eur J Surg Oncol, 40, 1706-1715

Gann PH, Hennekens CH, Stampfer MJ (1995). A prospective evaluation of plasma PSA for detection of prostate cancer. JAMA, 273, 289-94.

Heidenrich A, Bastian PJ, Bellmunt J, et al (2012). Guidelines on prostate cancer. Arnhem, Netherlands. European Association of Urology www.eau.org

Jemal A, Siegel R, Ward E et al (2008). Cancer statistics 2008. CA Cancer J Clin, 58, 71-96

Lalitha K, Suman G, Pruthvish S, et al (2012). Estimation of time trends of incidence of prostate cancer: an Indian scenario. Asian Pac J Cancer Prev, 13, 6245-50

Mitsuzuka K, Koie T, Narita S, et al (2014). Late pathological and oncological outcomes of elderly men treated with radical prostatectomy worse than those of younger men? Matched pair analysis between patients aged $<70$ and $>70$ years. $\mathrm{Jpn}$ J Clin Oncol, 44, 587-92.

Moreno JG, Croce CM, Fischer R, et al (1992). Detection of hematogenous micrometastasis in patients with prostate cancer. Cancer Res, 52, 6110-2

Murray NP, Reyes E, Badinez L, et al (2013), Circulating prostate cells found in men with benign prostate disease are P504S negative: clinical implications, J Oncology, 2013:165014.

Murray NP, Reyes E, Fuentealba C et al. (2014). Extended use of $\mathrm{P} 504 \mathrm{~S}$ positive primary circulating prostate cell detection to determine the need for initial prostate biopsy in a prostate cancer screening program in Chile. Asian Pac J Cancer Prev, 15, 9335-9.

Murray NP, Reyes E, Fuentealba C, et al (2014). Primary circulating prostate cells are not detected in low grade small volume prostate cancer. J Oncol, 2014, 612674.

NCCN clinical practical guidelines in oncology: prostate cancer 2014. Available at http://www.ncen.org

Panteleakou Z, Lembessis P, Sourla A et al. (2009), Detection of circulating tumor cells in prostate cancer patients:Methodological pitfalls and clinical relevance, Molecular Medicine, 15, 101-14.

Paterlini-Brechot P, Benali NL (2007). Circulating tumor cells (CTC) detection: Clinical impact and future directions, Cancer Letters, 253, 180-204.

Pavlakis K, Stravodimos K, Kapetanakis T et al (2010). Evaluation of routine application of P504S, 34 $\beta E 12$ and p63 immunostaining on 250 prostate needle biopsy specimens, Internat Urol Nephrol, 42, 325-30.

Punglia RS, D'Amico AV, Catalona WJ et al (2006). Impact of age, benign prostatic hyperplasia, and cancer on prostatespecific antigen level, Cancer, 106, 1507-13.

Ries LAG, Melbert D, Krapcho M et al (2009). SEER Cancer Statistics Review. 1975-2005 Betheseda MD: National Cancer Institute, 2008. Available at: http://seer.cancer. gov/csr/1975-2005, based on December 2009 SEER data submission.

Rubin MA, Zhou M, Dhanasekaran SM et al (2002). $\alpha$-methylacyl coenzyme A racemase as a tissue biomarker for prostate cancer, JAMA, 287, 1662-70.

Schroder FH, Hugosson J, Roobol MJ, et al (2009). Screening and prostate cancer mortality in a randomized European Study. NEJM, 360, 1320-8.

Situmorang GR, Umbas R, Mochtar CA et al (2012). Prostate cancer in younger and older patients: do we treat them differently? Asian Pac J Cancer Prev, 13, 4577-80

Sun L, Caire AA, Robertson CN, et al (2009). Men older than 70 years have higher risk prostate cancer and poorer survival in the early and late PSA eras. J Urol, 182, 2242-9

Verim L, Yildirim A, Basok ER, et al (2013). Impact of PSA and DRE on histologica findings at prostate biopsy in Turkish men over 75 years of age. Asian Pac J Cancer Prev, 14, 6085-8.

Walter LC, Covinsky KE (2001). Cancer screening in elderly patients: a framework for individual decision making. JAMA, 285, 2750-6

Went PT, Lugli A, Meier S, et al (2004). Frequent EpCam protein expression in human carcinomas. Human Pathology, 35, 122-8.

Zhou M, Chinnaiyan AM, Lleer CG, et al (2002). Alphamethylacyl-CoA racemase: a novel tumor marker overexpressed in several human cancers and their precursor lesions. Am J Surg Pathol, 26, 926-31. 